\title{
Can implant surfaces affect implant stability during osseointegration? A randomized clinical trial
}

\section{Luiz Carlos do CARMO FILHO(a) Raissa Micaella MARCELLO- MACHADO'(a) \\ Eduardo Dickie de CASTILHOS(b) Altair Antoninha DEL BEL CURY(a) Fernanda FAOT ${ }^{(c)}$}

\footnotetext{
(a) Universidade Estadual de Campinas - Unicamp, Piracicaba Dental School, Department of Prosthodontics and Periodontology, Piracicaba, SP, Brazil.

(b) Universidade Federal de Pelotas - UFPel, School of Dentistry, Department of Social and Preventive Dentistry, Pelotas, RS, Brazil. University of Campinas, Piracicaba, Brazil.

(c) Universidade Federal de Pelotas - UFPel, School of Dentistry, Department of Restorative Dentistry, Pelotas, RS, Brazil.
}

Declaration of Interests: The authors certify that they have no commercial or associative interest that represents a conflict of interest in connection with the manuscript.

Corresponding Author:

Fernanda Faot

E-mail: fernanda.faot@gmail.com

Submitted: July 12, 2018

Accepted for publication: August 17, 2018

Last revision: September 07, 2018
Abstract: This randomized clinical trial evaluated the insertion torque (IT), primary, and secondary stability of dental implants with different surface treatments during the osseointegration period. Nineteen patients with bilateral partial edentulism in the posterior mandibular region were randomly allocated to two implant brand groups and received implants with different surface treatments in the opposite site of the arch: Osseotite and Nanotite or SLA and SLActive. During implant placement, the maximum IT was recorded using a surgical motor equipped with a graphical user interface. The implant stability quotient (ISQ) was assessed immediately after the IT, and was measured weekly via resonance frequency analysis during 3 months. The data were analyzed by a one-way ANOVA, the Bonferroni test, paired $t$ tests and Pearson's correlation coefficient. The IT values were similar $(p>0.05)$ for all implant types ranging from $43.82 \pm 6.50$ to $46.84 \pm 5.06$. All implant types behaved similarly until the 28th day ( $p>0.05$ ). Between 35 and 56 days, Osseotite and SLActive showed lower ISQ values $(\mathrm{p}<0.001)$ compared to Nanotite and SLA implants. After 56 days, only Osseotite maintained significantly lower ISQ values than the other implants $(p<0.05)$. After 91 days the ISQ values were significantly higher than the baseline for all four implant types $(p<0.001)$. The ISQ and IT values were significantly correlated at the baseline and at the final evaluation for Osseotite, Nanotite, and SLActive implants $(\mathrm{p}<0.001)$. After 91 days, ISQ and IT values were only significantly correlated for the Osseotite implants $(p<0.05)$. All implants types exhibited acceptable primary and secondary stability.

Keywords: Dental Implants; Randomized Clinical Trials as Topic; Jaw, Edentulous, Partially.

\section{Introduction}

In recent decades, scientific progress has enabled widespread clinical applications for dental implants in the domain of oral rehabilitation through the implementation of simplified surgical techniques, innovations in macro- and microgeometry, and surface treatments. ${ }^{1,2,3}$. This evolution has ensured the applicability of these methods with high predictability for most healthy patients, and similar success rates have been seen for both the maxilla and the mandible. ${ }^{3}$ 
In compromised bone sites, the choice of implants with modified surfaces has directly influenced implant survival rates. ${ }^{1}$ Previous studies have shown that the bone quality is directly affected by the surface roughness of the implants. ${ }^{4,5}$ At the start of osseointegration, the adhesion of osteoblasts to the dental implant surface is insufficient to guarantee complete healing. This early adhesion is a prerequisite for osteoblast proliferation by mesenchymal cells. ${ }^{5}$ Increasing the surface roughness of the implants thus facilitates the retention of osteogenic cells and enables the faster migration of these cells to the implant surface via osteoconduction. ${ }^{1}$

However, many factors can influence the longterm osseointegration success of implants, especially those related to the host bone availability and microarchitectural properties, the surgical planning, and the dental implant properties. ${ }^{6,7}$ Dental implants thus require the implementation of an atraumatic surgical technique to reach primary stability. In addition, their biocompatibility, design, and surface characteristics should be observed to minimize the inflammatory responses, thus contributing to a favorable secondary stability. ${ }^{6,7}$

Modifications of the implant surface topography, structure, chemistry, surface charge, and wettability to achieve increased roughness have important influences on osseointegration. ${ }^{8}$ The final goal of implant surface modification is to create a more osteophilic surface, i.e., a surface that attracts bone-forming cells.,10 Both industry and research groups have examined modified titanium implant surfaces. Much research has focused on subtractive production methods, such as sandblasting and/or acid etching, and on methods involving the deposition of calcium phosphate crystals. Surface chemistry modifications that promote an extensive hydroxylation/hydration of the oxide layer have also been extensively researched, as this procedure should lead an interaction between surface atoms and the water shell around biomolecules, such as proteins. ${ }^{11}$ Hydrophilic titanium surfaces contribute to the acceleration and enhancement of bone apposition in animal models ${ }^{12}$ via the adsorption of proteins that impact the initial regulation of cellular adhesion. Finally, the stabilization of blood clots and early vascularization, which can be influenced by the surface of dental implants, may also play an essential role during the early stages of peri-implant wound healing. ${ }^{13,14}$ All the aforementioned modifications to bone-implant interfaces have reduced the healing period involved when using titanium implants. ${ }^{14,15}$

Non-hydrophilic implant surfaces have also enhanced bone apposition during the initial healing period and have shown favorable results when early-load protocols are applied. ${ }^{11}$ The mechanisms involved are based on a bone-bonding phenomenon involving an interdigitation of the cement line matrix of the bone with surface features of the underlying implant. ${ }^{13}$ Jonge et al., ${ }^{9}$ showed an increased adhesion of osteoblast-like cells to such coatings in an in vitro study. Calcium phosphate $(\mathrm{CaP})$ coatings are known to promote in vitro cell attachment and the production of extracellular matrix (ECM), whereas in vivo studies have confirmed the increased osteoconductive properties of $\mathrm{CaP}$ coatings when such implants were compared to non-coated implants. ${ }^{16,17}$ This favorable property of CaP coatings is thought to be related to the similarity in chemical composition between synthetic $\mathrm{CaP}$ and natural $\mathrm{CaP}$. Despite this chemical similarity, the deposited coatings do not show structural or biological similarity with bone tissue because natural bone also contains an organic matrix of collagen and non-collagenous proteins. Therefore, new techniques such as the electrostatic spray deposition of $\mathrm{CaP}$ have been explored in an attempt to promote osteoconductivity and osteogenesis and enhance osseointegration. Electrostatic $\mathrm{CaP}$ might be able to induce osteoblast attachment and consequently support cell differentiation and proliferation. ${ }^{18}$

Various studies ${ }^{4,5,19}$ have measured macro-, micro-, and nanoscale surface features of oral implants to investigate how these structures influence bone repair. However, very little is known about the clinical effects of modified physicochemical implants surfaces, especially regarding their primary stability, although it has been proven that primary stability can be enhanced by surface treatments. ${ }^{20}$ Currently, a large number of implant surface treatments are available. ${ }^{8}$ However, the effects of these treatments on primary or secondary stability during the early stages of osseointegration are still debated..$^{21}$ This longitudinal randomized clinical trial evaluated the 
primary and secondary stability and the insertion torque of dental implants with four different surfaces during the healing process.

\section{Methodology}

\section{Experimental design}

This double-blind split-mouth randomized clinical trial was conducted in accordance with the Helsinki Declaration, 2008, following the Consolidated Standards of Reporting Trials Statement (CONSORT) $)^{22}$ and aimed to evaluate the insertion torque and implant stability of dental implants with four different implant surfaces in the posterior region of the mandible. This study was performed at the dental clinic of the São Leopoldo Mandic Dental Research Center (Campinas / SP) and was approved by the Ethics Research Committee of this research center under protocol number 2010/0262. All patients enrolled in this study signed informed consent forms and provided medical health histories before treatment.

The sample size calculation was based on the implant stability quotient (ISQ) means and SD of SLA RN $(76.5 \pm 6.5)$ and SLActive $(78.8 \pm 3.20)$ groups at 12 weeks recorded in a previous study ${ }^{25}$. The following parameters were used: the smallest expected difference between the means; the standard deviation of the difference between the means; a beta error of $20 \%$, an alpha error of $5 \%$ and an effect size of 0.91 , as indicated by a sensitivity analysis. These calculations indicated that each group should include a minimum of 20 implants.

The following inclusion criteria were applied: ASA type I patients without physiological, biochemical or psychiatric illnesses, non-smokers, D2 and/or D3 class bone density, ${ }^{23}$ bone quantity class A and/ or $\mathrm{B}^{24}$ and bilaterally edentulous in the mandibular region. Patients with poorly controlled diabetes, a recent history of heart surgery, heart attack, stroke, or the recent use of anticoagulant drugs or the longterm use of bisphosphonate medication were excluded from the study. Furthermore, patients who required bone grafting, barrier membranes, or immediate loading were also excluded from the study. Finally, any dental implant that did not reach an insertion torque of $30 \mathrm{Ncm}$ during the installation was removed from the analyzed dataset. Prior to surgery, patients received a comprehensive periodontal examination. All patients underwent a periapical and panoramic radiograph of the prospective areas for implant placement to determine the implant length. The bone site thickness was clinically evaluated using a bone measuring caliper. When the bone quantity or quality was unclear, a computerized tomogram of the elected hemi-arch was performed before surgery.

Four implant types of two brands comprised the four groups under study: Group I - Osseotite ${ }^{\circledR}$ (prepared using double acid etching; Biomet-3i, West Palm Springs, FL); Group II - Nanotite ${ }^{\circledR}$ (prepared using double acid etching with the discrete nanoscale deposition of CaP crystals; Biomet-3i, West Palm Springs, USA); Group III - SLA® (prepared using jets of corundum particles followed by acid etching; Straumann AG - Basel, Switzerland); and Group IV SLActive ${ }^{\circledR}$ (chemically activated by surface blasting with corundum followed by acid etching, made hydrophilic by washing under a $\mathrm{N}_{2}$ atmosphere with isotonic acid and subsequently immersed in $\mathrm{NaCl}$, Straumann AG - Basel, Switzerland). All implants had a cylindrical body with similar dimensions: diameters of 4.0-4.1 mm and implant lengths of $8-11.5 \mathrm{~mm}$. The implant length was selected according to the bone availability. The dental implants in group I and II had triangular threads with small/short thread pitches and cutting apex, while implants of groups III and IV had triangular threads with pitch wide/long holes and apex threads. The drilling protocols followed were those recommended by the manufacturers.

To randomize the patients and implant surface treatments, we used a computer-generated list created by an independent researcher (RMMM). The implant selection was determined by allocating the implant brand (Biomet-3i or Straumann) and the implant surface in each posterior hemi-arch according to the list generated by the algorithm. The patient and the single calibrated evaluator were blinded with respect to the location of each implant in the mandibular arch.

The insertion torque (IT) values were determined as the maximum torque value $(\mathrm{Ncm})$ reached at the end of the implant insertion. The IT was measured using a surgery drilling unit (Kavo Koncept Surg, Kavo do Brasil, Joinvile, Brazil) equipped with a 
graphical user interface with an accurate display of maximum torque (up to $80 \mathrm{Ncm}$ ) and a motor speed fitted with a 27:1 surgical contra-angle (KAVO Dental $\mathrm{GmbH}$, Biberach, Germany). After the final seating of the implant, a type 17 or type 45 Smartpeg® was installed, and resonance frequency analysis (RFA) was performed to record the primary stability (PS) using an Osstell Mentor ${ }^{\circledR}$ device (Ostell/Integration Diagnostics, Goteborg, Sweden). The implant stability quotient values (ISQ) were recorded in the buccal and the mesial directions, both oriented perpendicular to the transducer. The ISQ value for each implant surface was then calculated as the mean value of the two faces. The secondary stability (SS) of the implant was also recorded on a weekly basis between 7 and 91 days post-surgery

Straight healing abutments were inserted after implant installation. The incision was sutured with 5.0 Nylon (Bioline Fios Cirúrgicos Ltda, Anápolis, Brazil) using simple interrupted stitches, which were removed one week after surgery (Figure 1). All patients were instructed to follow a doughy-like and cold diet during the first three days after surgery. To control biofilm accumulation, the patients were instructed to use a soft toothbrush and a mouthwash containing $0.2 \%$ chlorhexidine digluconate twice daily during the first week. These instructions were reinforced at each follow-up. All patients received a prescription for Azithromycin (500 mg, 1 tablet every 24 hours for 3 days) starting 1 hour before surgery. In addition, dexamethasone $(4 \mathrm{mg}$, 1 tablet every 24 hours for 3 days) and Lisador or Paracetamol (500 mg, 1 tablet every 6 hours for 5 days) were prescribed after the surgery.

\section{Statistical analysis}

The data were first analyzed using one-way ANOVA. The Bonferroni test was then used to compare implant surface treatments at different time points, and paired t tests were used to compare each implant surface treatment between the time points. Pearson's correlation coefficients (r) between the IT and ISQ were calculated. The significance level was set at $5 \%$ for all analyses.

\section{Results}

A flow chart for the study is shown in Figure 2. A total of 80 implants were installed in 19 patients (12 women and 7 men) with a mean age of 46.7 years. No patients were lost during the follow-up period. All dental implants had similar dimensions,
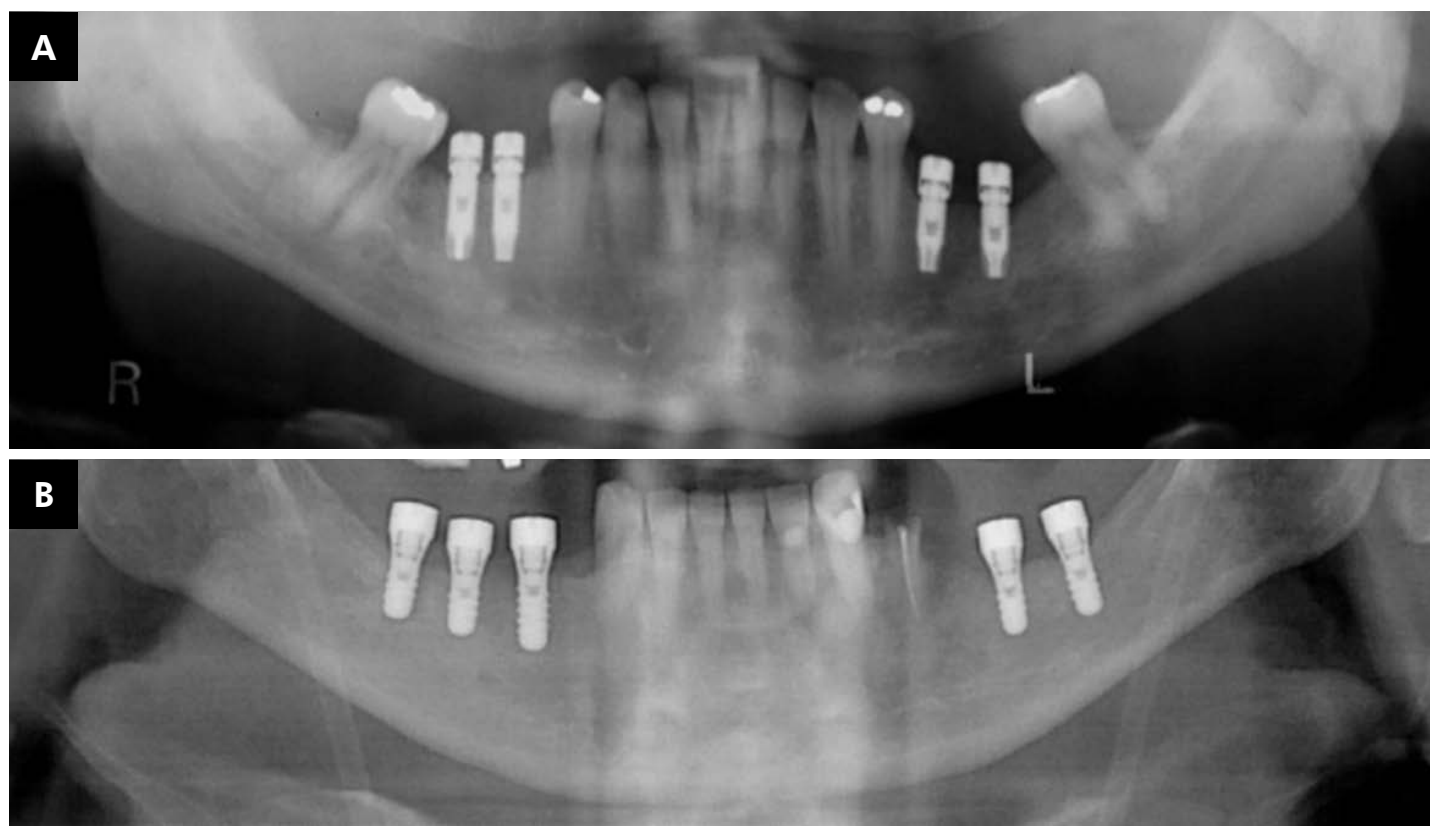

Figure 1. Split-mouth clinical design: a.) Osseotite $x$ Nanotite; b) SLA x SLActive 


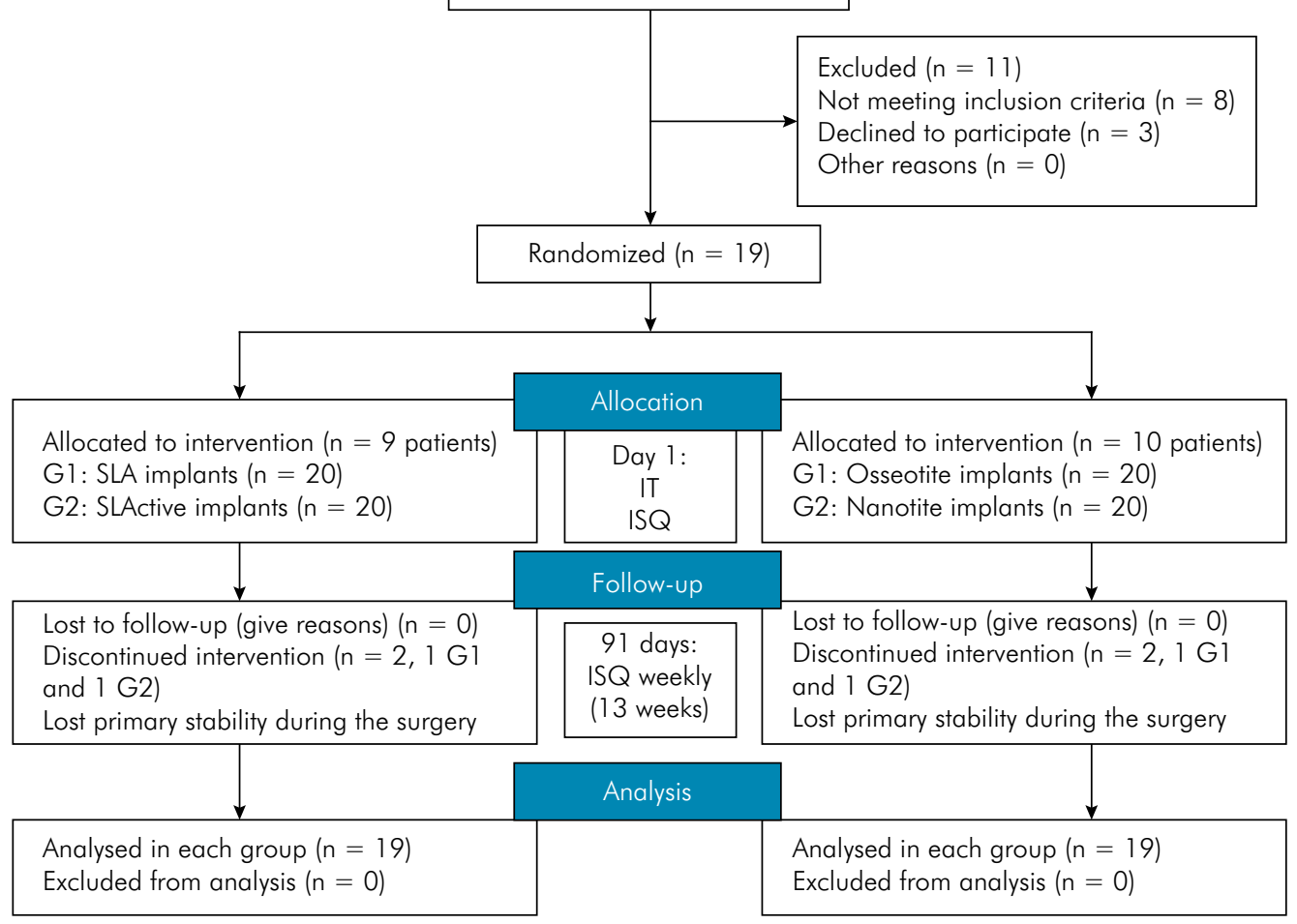

Figure 2. Consort flow diagram.

with diameters that varied from 4.0 to $4.1 \mathrm{~mm}$ and with lengths between 8 and $11.5 \mathrm{~mm}$. The implants used in this study are listed according to their commercial brand, dimensions, and surfaces in Table 1 and are graphically shown according to the edentulous region of the posterior mandible in Figure 3. Four implants, one in each group, did not reach the minimum insertion torque (IT) of $30 \mathrm{Ncm}$ required. No significant differences $(p>0.05)$ were observed between the insertion torque values according to the implant type. The obtained IT values (mean $\pm \mathrm{sd}$ ) were as follows: Osseotite $=44.47 \pm 6.64$; Nanotite $=46.84 \pm 5.06$; SLA $=43.82 \pm 6.50$ and SLAactive $=43.95 \pm 6.14$.

All implant types behaved similarly until the 28 th day $(\mathrm{p}>0.05)$. After 35 days, Osseotite and SLActive implants showed significantly lower ISQ values than Nanotite and SLA implants $(p<0.001)$, and this difference persisted until 56 days. After 56 days, Osseotite maintained significantly lower ISQ values $(p<0.05)$ than the other implant types. After
Table 1. Distribution of implants used in the study according to their commercial brands and dimensions $(n=80)$.

\begin{tabular}{lcccccc}
\hline \multirow{2}{*}{ Surface } & \multicolumn{5}{c}{ Dimension of implants $(\mathrm{mm})$} \\
\cline { 2 - 6 } & $4.0 \times 8.5$ & $4.0 \times 10$ & $4.0 \times 11.5$ & $4.1 \times 8.0$ & $4.1 \times 10$ \\
\hline Osseotite & 2 & 10 & 8 & $\mathrm{x}$ & $\mathrm{x}$ \\
Nanotite & 5 & 10 & 5 & $\mathrm{x}$ & $\mathrm{x}$ \\
SLA & $\mathrm{x}$ & $\mathrm{x}$ & $\mathrm{x}$ & 4 & 16 \\
SLActive & $\mathrm{x}$ & $\mathrm{x}$ & $\mathrm{x}$ & 8 & 12 \\
\hline
\end{tabular}

91 days, the ISQ values for all analyzed implant types were significantly higher than the primary ISQ value $(p<0.001)$. SLA and SLActive exhibited the highest ISQ values ( $p<0.001)$, and Osseotite had the lowest values $(\mathrm{p}<0.001)$. Table 2 lists the correlation coefficients between ISQ and IT values at critical time points. At the baseline evaluation, IT and ISQ were significantly correlated for all evaluated implant types except SLA types ( $p>0.05)$. At 91 days, IT was significantly correlated with ISQ only for the Osseotite implants $(\mathrm{p}<0.0002)$. 


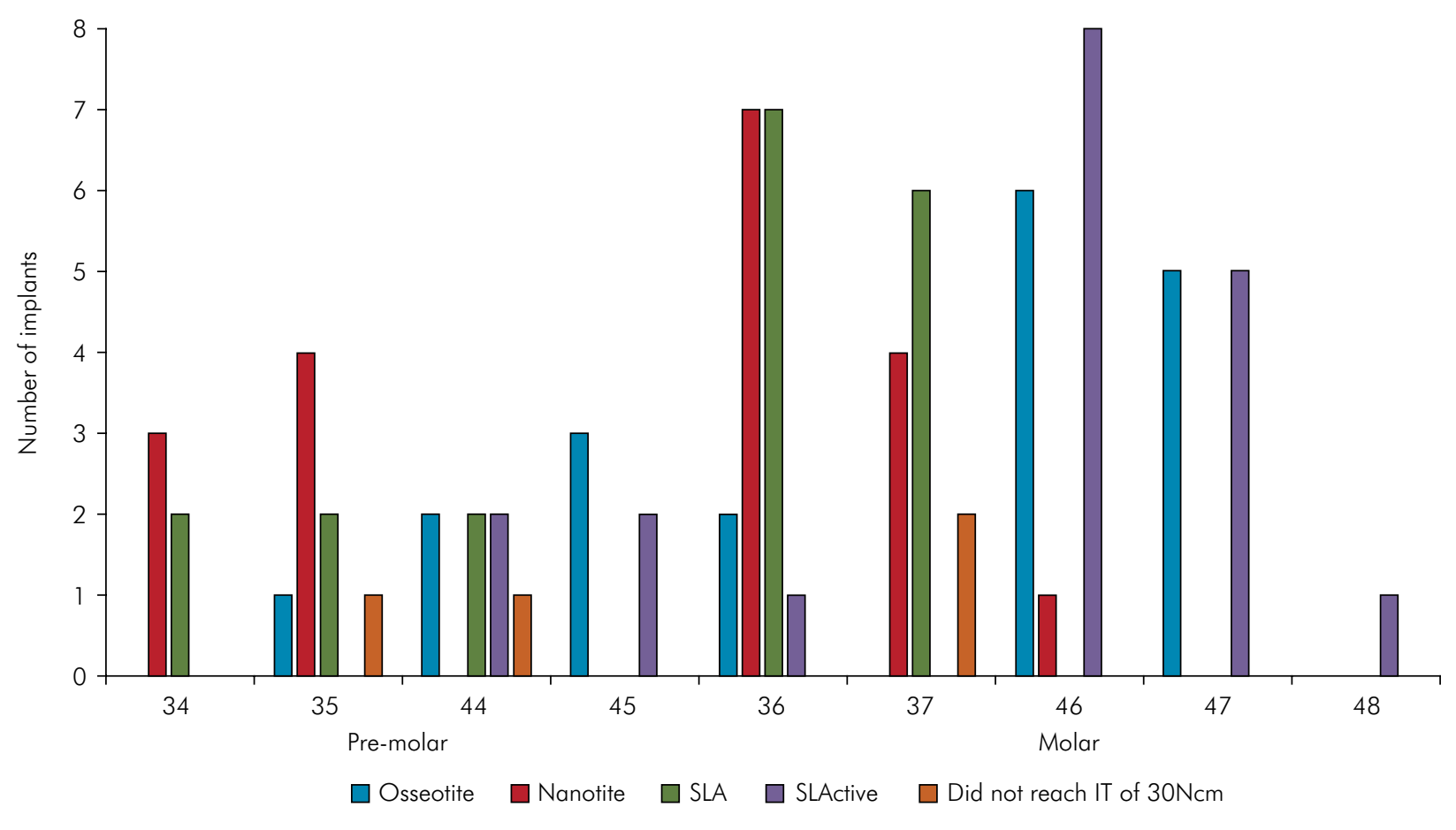

Figure 3. Distribution of the implant sites.

Table 2. Correlation between IT and ISQ in the critical time points.

\begin{tabular}{|c|c|c|c|c|c|}
\hline \multirow{2}{*}{ Implant surfaces } & \multicolumn{5}{|c|}{ Time Intervals (days) } \\
\hline & 0 & 21 & 42 & 63 & 91 \\
\hline \multirow{2}{*}{ Nanotite } & 0.83451 & 0.61083 & 0.68315 & 0.65956 & 0.48054 \\
\hline & $<.0001 S$ & $0.0055 \mathrm{~S}$ & 0.00135 & $0.0021 \mathrm{~S}$ & $0.0373 \mathrm{NS}$ \\
\hline \multirow{2}{*}{ Osseotite } & 0.91995 & 0.75725 & 0.72751 & 0.69178 & 0.75407 \\
\hline & $<.0001 \mathrm{~S}$ & 0.00025 & $0.0004 \mathrm{~S}$ & $0.0010 \mathrm{~S}$ & $0.0002 \mathrm{~S}$ \\
\hline \multirow{2}{*}{ SLA } & 0.43911 & 0.58010 & 0.28658 & 0.45557 & 0.11381 \\
\hline & $0.0778 \mathrm{NS}$ & 0.01465 & $0.2648 \mathrm{NS}$ & $0.0661 \mathrm{NS}$ & $0.6636 \mathrm{NS}$ \\
\hline \multirow{2}{*}{ SLActive } & 0.85445 & -0.10194 & -0.09812 & 0.05133 & 0.13903 \\
\hline & $<.0001 S$ & $0.6780 N S$ & $0.6894 \mathrm{NS}$ & $0.8347 N S$ & $0.5703 \mathrm{NS}$ \\
\hline
\end{tabular}

S: Significant correlation; NS: non-significant correlation.

Figures 4 and 5 show the implant stability as a function of time. The intra-group comparisons showed an ISQ minimum at 21 days for the SLActive implants (78.8 \pm 2.6$)$, and their ISQ was significantly higher at 63 days $(80.2 \pm 2.4)$. The minimum ISQ for the SLA $(79.5 \pm 2.8)$ and Nanotite implants $(78.4 \pm 3.2)$ occurred at 28 days, and the ISQ increased gradually from 42 days onwards. The Osseotite implants showed the lowest mean ISQ at 35 days $(75.5 \pm 5.6)$, and the
ISQ then increased significantly and continuously until 91 days.

\section{Discussion}

A wide diversity of implant brands currently exists, and many types of materials have been developed by research scientists and private industry. Therefore, organized comparative information for clinicians is 
Osseotite

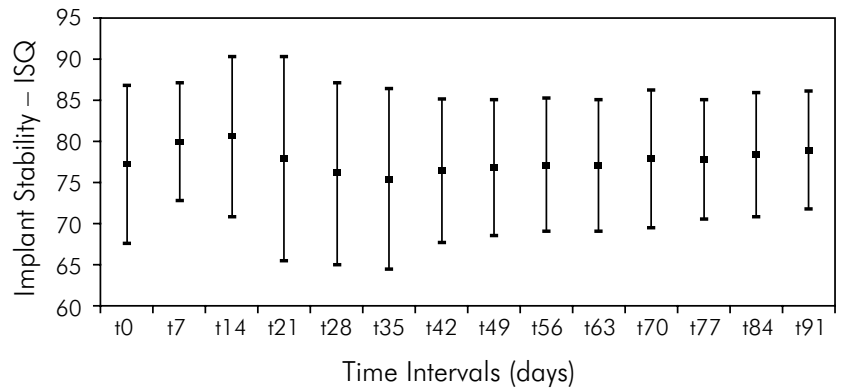

SLA

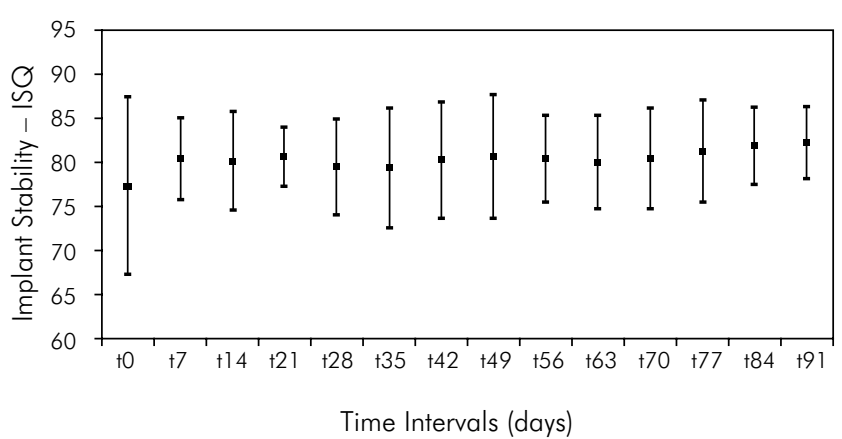

Nanotite

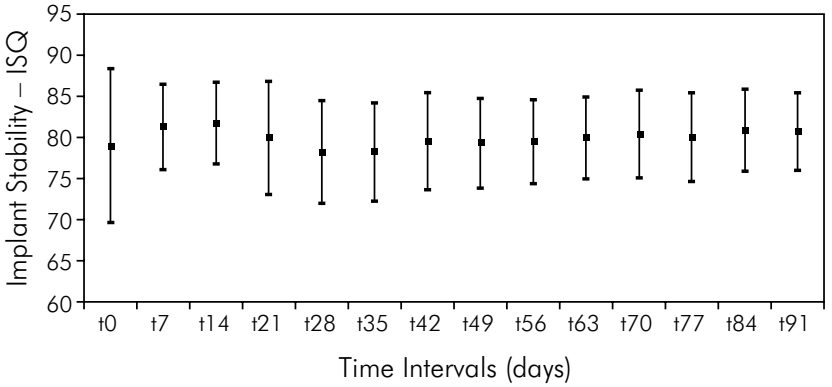

SLActive

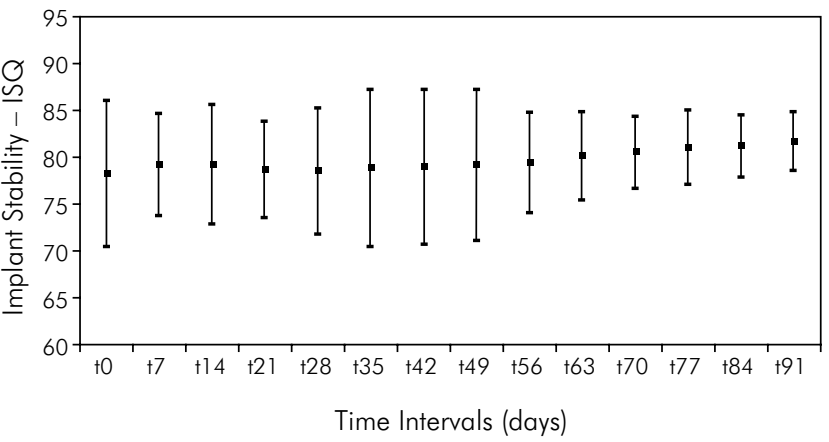

Figure 4. Range of Implant stability values (Mean, upper, and lower interval) as a function of time according to the implant types.

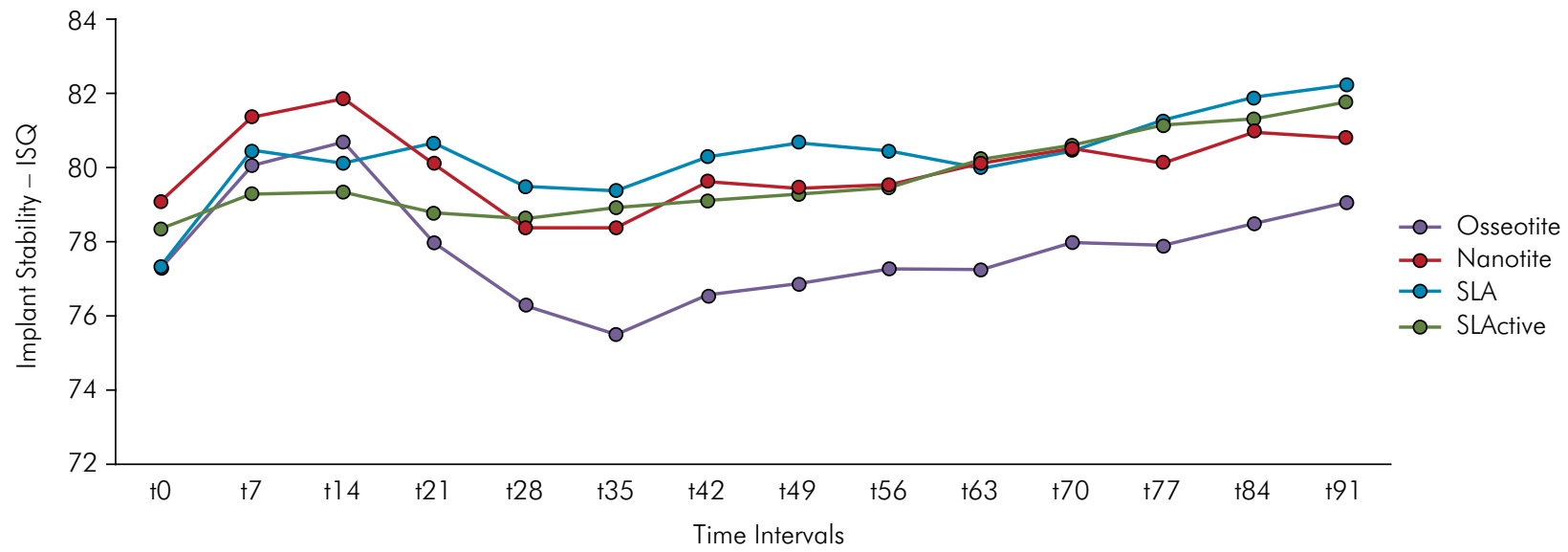

\begin{tabular}{|c|c|c|c|c|c|c|c|c|c|c|c|c|c|c|}
\hline & to & †7 & $t 14$ & t21 & t28 & 135 & 142 & 149 & 156 & 163 & t70 & †77 & 184 & 191 \\
\hline Osseotite & $77 \pm 4.9$ & $8.0 \pm 3.6$ & $81 \pm 5.0$ & $79 \pm 6.3$ & $76 \pm 5.6$ & $76 \pm 5.6$ & $77 \pm 4.5$ & $77 \pm 4.2$ & $77 \pm 4.1$ & $77 \pm 4.1$ & $78 \pm 4.3$ & $78 \pm 3.7$ & $79 \pm 3.9$ & $79 \pm 3.7$ \\
\hline Nanotite & $79 \pm 4.8$ & $81 \pm 2.7$ & $82 \pm 2.6$ & $80 \pm 3.5$ & $78 \pm 3.2$ & $78 \pm 3.0$ & $80 \pm 3.0$ & $79 \pm 2.8$ & $80 \pm 2.6$ & $80 \pm 2.5$ & $81 \pm 2.7$ & $80 \pm 2.7$ & $81 \pm 2.6$ & $81 \pm 2$. \\
\hline SLA & $77 \pm 5.2$ & $80 \pm 2.4$ & $80 \pm 2.9$ & $81 \pm 1.7$ & $80 \pm 2.8$ & $79 \pm 3.5$ & $80 \pm 3.4$ & $81 \pm 3.6$ & $80 \pm 2.5$ & $80 \pm 2.7$ & $80 \pm 2.9$ & $81 \pm 3.0$ & $82 \pm 2.2$ & $82 \pm 2.1$ \\
\hline SLActive & $78 \pm 4.0$ & $79 \pm 2.8$ & $79 \pm 3.3$ & $79 \pm 2.6$ & $79 \pm 3.5$ & $79 \pm 4.3$ & $79 \pm 4.2$ & $79 \pm 4.1$ & $79 \pm 2.7$ & $80 \pm 2.4$ & $81 \pm 2.4$ & $81 \pm 2.1$ & $81 \pm 1.7$ & $82 \pm 1.6$ \\
\hline
\end{tabular}

Figure 5. The ISQ of all implant surfaces as a function of time (mean $\pm S D$ ). 
essential to enable the rapid and accurate selection of implant systems with optimal cost-benefit ratios. Therefore, our clinical trial adopted a split-mouth design to control for possible confounding factors, such as patient-specific characteristics related to bone-healing capacity, general health condition, and habits. During the 90-day follow-up of this study, the studied Osseotite, Nanotite, SLA and SLActive implants all showed acceptable primary and secondary stability with ISQ means above 75 . However, when we compared the different implant types, Osseotite presented the lowest ISQ values.

Our results show a high implant stability profile for all studied surfaces across all evaluated times (Figures 4 and 5). These results are similar to those reported by Han et al. ${ }^{25}$ in a study that determined the influence of surface type and diameter on the stability of implants during the early phase of osseointegration for SLActive and SLA implants. These authors also reported that after 12 weeks, no significant differences were found for ISQ values depending on surface or implant diameter. This behavior was attributed to the time dependency of bone remodeling observed at the initial stage. Therefore, bone shape and remodeling toward the implant surfaces interferes with the boneimplant contact interface. ${ }^{15,26}$

To standardize the sample population to control for confounding factors, we selected homogenous bone sites and implants with similar dimensions, which contributed to our favorable ISQ results. Sim and Lang ${ }^{27}$ investigated the influence of bone density structure, implant length, and the position of the measuring instrument on resonance frequency analyses and concluded that variations in the ISQ values are not related to the position of the measuring instrument. Instead, the bone structure and implant length around the implant mainly influences ISQ. The small variation in implant length $(8-11.5 \mathrm{~mm})$ may have influenced the ISQ values. Unfortunately, it is impossible to completely control for this potential confounding factor as the variation is determined by the available lengths for each brand. Moreover, in the clinical study by Sim and Lang, ${ }^{27}$ the ISQ values for implants with lengths of 8 and $10 \mathrm{~mm}$ were significantly different only at the time of surgery. Furthermore, because the number of implants used per group in this study was relatively low and the implants were grouped irrespective of the bone type, it is difficult to determine to what degree the implant length is a predictive factor for ISQ. In this RCT, only 7 of 40 installed implants were short in the $3 i$ brand subgroups, while 12 of 40 implants in the Straumann subgroups were short. The correlations between IT and ISQ in this study (Table 2) suggest that the implant length might influence the relationship between IT and ISQ over time as the smallest number of short implants $(n=2)$ was installed in the Osseotite implants group, and this group presented significant correlations between ISQ and IT at all critical time intervals during healing.

In this study, one implant surface of each tested sample group was lost due to a low initial insertion torque. Nevertheless, the mean IT values showed that the bone quality of the bone site provided a favorable prognosis in terms of bone anchorage, allowing the adoption of an immediate loading protocol. Alsaadi et al., ${ }^{28}$ and Turkyilmaz et al., ${ }^{29}$ also reported that bone density affected the primary implant stability. Furthermore, they found a significant correlation between insertion torque and PS as measured by RFA and concluded that these methods are effective for evaluating implant stability.

Although the insertion torque of the different implant surfaces did not significantly differ $(p>0.05)$, they showed a strong correlation with the ISQ values at all evaluated times. However, the correlation between the primary and secondary stability as evaluated by resonance frequency analysis and the installation torque has only been observed in a few studies, and the obtained results appear contradictory. ${ }^{30,31,32,33,34}$. Factors such as a lack of homogeneity of the implant receptor site, differences in bone density, drilling techniques, friction coefficient during implant installation, thread geometry and implant shape, implant surface treatment, and even the model used for statistical analysis can influence the relation between torque and resonance frequency analysis. ${ }^{35} \mathrm{~A}$ recent systematic review by Lages et al., ${ }^{36}$ found no correlation between insertion torque and primary stability, indicating that a high insertion torque does not necessarily correspond to a high ISQ. 
With regard to the biological behavior of implant surfaces, Ostmann et al. ${ }^{37}$ emphasize that while new surface textures such as those achieved by nanoscale calcium phosphate incorporation improve early setting and morphometric bone formation in preclinical studies and human studies; however, these surfaces only have a clear cost-benefit outcome when immediate loading is applied. The clinical implications of our results are consistent with this statement and indicate that implants with different surfaces can reach similar implant-bone interface rigidity, despite a small but significant ISQ difference at approximately 35 days. Thus, when a fast rehabilitation using immediate loading is not required, clinicians should prioritize evaluating the patient's characteristics and their surgical experience over evaluating the implant surface modifications available on the market.

Regarding hydrophilic surfaces, Novellino et al., ${ }^{38}$ suggest that hydrophilic surface implants osseointegrate faster than sandblasted and acid-etched implants. In addition, these authors demonstrated that the ISQ of hydrophilic implants increased 2.24 times faster than implants treated with blasting and acid etching. However, in our longitudinal clinical study, it was shown that Nanotite ${ }^{\circledR}$ (double acid-etched with the discrete nanoscale deposition (DCD®) of CaP crystals), SLA® (sandblasted $\mathrm{Al}_{2} \mathrm{O}_{3}$ cored and acid-etched) and SLActive ${ }^{\circledR}$ (chemically treated sandblasted and acid-etched surfaces with hydrophilic properties) induced higher biological activity than Osseotite ${ }^{\circledR}$ (double acid-etched) surface implants at the end of the 91-day evaluation period. Furthermore, both the SLA® and SLActive surface implants were superior to the Nanotite ${ }^{\circledR}$ surface $(\mathrm{P}<0.05)$. Gupta and Padmanabhan ${ }^{39}$ argue that primary implant stability is a mechanical phenomenon that is related to the local bone quality and quantity, implant type, surgical techniques used, and installation. The application of a simple, clinically applicable noninvasive tool to evaluate implant stability and osseointegration is considered highly desirable. ${ }^{40}$ Therefore, the clinical applicability of resonance frequency analysis (RFA) should be encouraged as a tool to test implant suitability for immediate loading protocols (ISQ $\geq 70$ ), ${ }^{36}$ to dictate biologic prognosis, and for monitoring the long-term behavior of implants.

Although this RCT was able to detect different bone behavior during the osseointegration period for the various studied implant surfaces, this prospective clinical study was conducted using a relatively small sample size, examined implants with small length variations, and used a short follow-up time. We therefore suggest that future studies investigate these effects between 21 and 42 days after installation. During this period in the healing process, we noticed a subtle reduction in stability for all chemically inactive surfaces. Our results provide useful clinical information that can be investigated using different time frames. For instance, the secondary implant stability of the Osseotite implants was lower than the other implant surfaces only after 42 days of healing. All other tested implant surfaces showed a slight reduction in the ISQ values after installation, reaching minimum stability levels at 21 days post-operation and increasing from 63 days onwards.

\section{Conclusion}

Osseotite, Nanotite, SLA, and SLActive implant types all exhibited acceptable primary and secondary stability. The most important interval for osseointegration occurred at approximately 35 days for the Osseotite and SLActive implants.

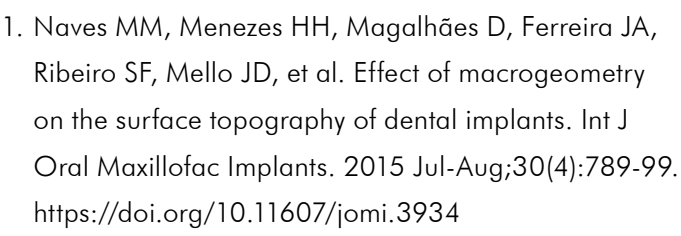

\section{References}


3. Strietzel FP, Karmon B, Lorean A, Fischer PP. Implantprosthetic rehabilitation of the edentulous maxilla and mandible with immediately loaded implants: preliminary data from a retrospective study, considering time of implantation. Int J Oral Maxillofac Implants. 2011 Jan-Feb;26(1):139-47.

4. Fröjd V, Wennerberg A, Stenport VF. Importance of $\mathrm{Ca}(2+)$ modifications for osseointegration of smooth and moderately rough anodized titanium implants - a removal torque and histological evaluation in rabbit. Clin Implant Dent Relat Res. 2012 Oct;14(5):737-45. https://doi.org/10.1111/j.1708-8208.2010.00315.x

5. Elias LS, Costa RF, Carvalho MA, Batista AC, Silva TA, Leles $C R$ et al. Markers of bone remodeling in neoplastic and bone-related lesions. Oral Surg Oral Med Oral Pathol Oral Radiol Endod. 2010 Nov; 110(5):624-31. https://doi.org/10.1016/i.tripleo.2010.06.014

6. Romanos GE, Basha-Hijazi A, Gupta B, Ren YF, Malmstrom $H$. Role of clinician's experience and implant design on implant stability. An ex vivo study in artificial soft bones. Clin Implant Dent Relat Res. 2014 Apr;16(2):166-71. https://doi.org/10.1111/j.1708-8208.2012.00470.x

7. Huwais S, Meyer EG. A novel osseous densification approach in implant osteotomy preparation to increase biomechanical primary stability, bone mineral density, and bone-to-implant contact. Int J Oral Maxillofac Implants. 2017 Jan/Feb;32(1):27-36. https://doi.org/10.11607/jomi.4817

8. Albrektsson T, Wennerberg A. Oral implant surfaces: Part 1-review focusing on topographic and chemical properties of different surfaces and in vivo responses to them. Int J Prosthodont. 2004 Sep-Oct;17(5):536-43.

9. Jonge LT, Leeuwenburgh SC, Beucken JJ, Riet J, Daamen WF, Wolke JG et al. The osteogenic effect of electrosprayed nanoscale collagen/calcium phosphate coatings on titanium. Biomaterials. 2010 Mar;31(9):2461-9. https://doi.org/10.1016/i.biomaterials.2009.11.114

10. Mendonça G, Mendonça DB, Aragão FJ, Cooper LF. Advancing dental implant surface technology - from micron- to nanotopography. Biomaterials. 2008 Oct;29(28):3822-35. https://doi.org/10.1016/i.biomaterials.2008.05.012

11. Bornstein MM, Hart CN, Halbritter SA, Morton D, Buser $D$. Early loading of nonsubmerged titanium implants with a chemically modified sand-blasted and acid-etched surface: 6 -month results of a prospective case series study in the posterior mandible focusing on peri-implant crestal bone changes and implant stability quotient (ISQ) values. Clin Implant Dent Relat Res. 2009 Dec;11(4):338-47. https://doi.org/10.1111/j.1708-8208.2009.00148.x

12. Buser D, Broggini N, Wieland M, Schenk RK, Denzer AJ, Cochran DL et al. Enhanced bone apposition to a chemically modified SLA titanium surface. J Dent Res. 2004 Jul;83(7):529-33. https://doi.org/10.1177/154405910408300704
13. Davies JE. Understanding peri-implant endosseous healing. J Dent Educ. 2003 Aug;67(8):932-49.

14. Gottlow J, Barkarmo S, Sennerby L. An experimental comparison of two different clinically used implant designs and surfaces. Clin Implant Dent Relat Res. 2012 May;14 Suppl 1:e204-12. https://doi.org/10.1111/j.1708-8208.2012.00439.x

15. Oates TW, Valderrama P, Bischof $M$, Nedir R, Jones A, Simpson J et al. Enhanced implant stability with a chemically modified SLA surface: a randomized pilot study. Int J Oral Maxillofac Implants. 2007 Sep-Oct;22(5):755-60.

16. Siebers MC, Walboomers XF, Leeuwenburgh SC, Wolke JG, Jansen JA. Electrostatic spray deposition (ESD) of calcium phosphate coatings, an in vitro study with osteoblastlike cells. Biomaterials. 2004 May;25(11):2019-27. https://doi.org/10.1016/i.biomaterials.2003.08.050

17. Siebers MC, Walboomers XF, Dolder J, Leeuwenburgh SC, Wolke JG, Jansen JA. The behavior of osteoblast-like cells on various substrates with functional blocking of integrin- $\beta 1$ and integrin- $\beta 3$. J Mater Sci Mater Med. 2008 Feb;19(2):861-8. https://doi.org/10.1007/s10856-007-0166-6

18. He W, Andersson M, Souza PP, Costa CAS, Muñoz EM, Schwartz-Filho $\mathrm{HO}$ et al. Osteogenesis-inducing calcium phosphate nanoparticle precursors applied to titanium surfaces. Biomed Mater. 2013 Jun;8(3):035007. https://doi.org/10.1088/1748-6041/8/3/035007

19. Wennerberg A, Albrektsson T. Structural influence from calcium phosphate coatings and its possible effect on enhanced bone integration. Acta Odontol Scand. 2009;67(6):333-40. https://doi.org/10.1080/00016350903188325

20. Mazzo CR, Reis AC, Shimano AC, Valente ML. In vitro analysis of the influence of surface treatment of dental implants on primary stability. Braz Oral Res. 2012 Jul-Aug;26(4):313-7. https://doi.org/10.1590/S1806-83242012005000006

21. Javed F, Almas K, Crespi R, Romanos GE. Implant surface morphology and primary stability: is there a connection? Implant Dent. 2011 Feb;20(1):40-6. https://doi.org/10.1097/ID.0b013e31820867da

22. Moher D, Hopewell S, Schulz KF, Montori V, Gøtzsche PC, Devereaux PJ et al. CONSORT 2010 explanation and elaboration: updated guidelines for reporting parallel group randomised trials. BMJ. 2010;340:c869. https://doi.org/10.1136/bmi.c869

23. Misch CE, Hoar J, Beck G, Hazen R, Misch CM. A bone quality-based implant system: a preliminary report of stage I \& stage II. Implant Dent. 1998;7(1):35-42. https://doi.org/10.1097/00008505-199804000-00004

24. Lekholm U, Zarb G. Patient selection and preparation. Chicago: Tissue Integr Prostheses Quintessance; 1985. p. 199-209. 
25. Han J, Lulic M, Lang NP. Factors influencing resonance frequency analysis assessed by Osstell mentor during implant tissue integration: II. Implant surface modifications and implant diameter.

Clin Oral Implants Res. 2010 Jun;21(6):605-11. https://doi.org/10.1111/j.1600-0501.2009.01909.x

26. Abrahamsson I, Berglundh T, Linder E, Lang NP, Lindhe J. Early bone formation adjacent to rough and turned endosseous implant surfaces. An experimental study in the dog. Clin Oral Implants Res. 2004 Aug;15(4):381-92. https://doi.org/10.1111/j.1600-0501.2004.01082.x

27. Sim CP, Lang NP. Factors influencing resonance frequency analysis assessed by Osstell mentor during implant tissue integration: I. Instrument positioning, bone structure, implant length. Clin Oral Implants Res. 2010 Jun;21(6):598-604. https://doi.org/10.1111/j.1600-0501.2009.01878.x

28. Alsaadi G, Quirynen M, Michiels K, Jacobs R, Steenberghe D. A biomechanical assessment of the relation between the oral implant stability at insertion and subjective bone quality assessment. J Clin Periodontol. 2007 Apr;34(4):359-66. https://doi.org/10.1111/j.1600-051X.2007.01047.x

29. Turkyilmaz I, Sennerby L, McGlumphy EA, Tözüm TF. Biomechanical aspects of primary implant stability: a human cadaver study. Clin Implant Dent Relat Res. 2009 Jun;11(2):113-9. https://doi.org/10.1111/j.1708-8208.2008.00097.x

30. Magno Filho LC, Cirano FR, Hayashi F, Hsu FS, Alexandre C, Dib L et al. Assessment of the correlation between insertion torque and resonance frequency analysis of implants placed in bone tissue of different densities. J Oral Implantol. 2014 Jun;40(3):259-62. https://doi.org/10.1563/AAID-JOI-D-11-00183.1

31. Kahraman S, Bal BT, Asar NV, Turkyilmaz I, Tözüm TF. Clinical study on the insertion torque and wireless resonance frequency analysis in the assessment of torque capacity and stability of self-tapping dental implants. J Oral Rehabil. 2009 Oct;36(10):755-61. https://doi.org/10.1111/j.1365-2842.2009.01990.x

32. Turkyilmaz I. A comparison between insertion torque and resonance frequency in the assessment of torque capacity and primary stability of Brånemark system implants. J Oral Rehabil. 2006 Oct;33(10):754-9. https://doi.org/10.1111/j.1365-2842.2006.01631.x

33. Miyamoto I, Tsuboi Y, Wada E, Suwa H, lizuka T. Influence of cortical bone thickness and implant length on implant stability at the time of surgery-clinical, prospective, biomechanical, and imaging study. Bone. $2005 \mathrm{Dec} ; 37(6): 776-80$. https://doi.org/10.1016/i.bone.2005.06.019

34. Nkenke E, Hahn M, Weinzierl K, Radespiel-Tröger M, Neukam FW, Engelke K. Implant stability and histomorphometry: a correlation study in human cadavers using stepped cylinder implants. Clin Oral Implants Res. 2003 Oct;14(5):601-9. https://doi.org/10.1034/i.1600-0501.2003.00937.x

35. Santos MV, Elias CN, Lima JHC. The effects of superficial roughness and design on the primary stability of dental implants. Clin Implant Dent Relat Res. 2011 Sep;13(3):21523. https://doi.org/10.1111/j.1708-8208.2009.00202.x

36. Lages FS, Douglas-de Oliveira DW, Costa FO. Relationship between implant stability measurements obtained by insertion torque and resonance frequency analysis: A systematic review. Clin Implant Dent Relat Res. 2018 Feb;20(1):26-33. https://doi.org/10.1111/cid.12565

37. Ostman PO, Wennerberg A, Albrektsson T. Immediate occlusal loading of NanoTite PREVAIL implants: a prospective 1-year clinical and radiographic study. Clin Implant Dent Relat Res. 2010 Mar;12(1):39-47. https://doi.org/10.1111/j.1708-8208.2008.00128.x

38. Novellino MM, Sesma N, Zanardi PR, Laganá DC. Resonance frequency analysis of dental implants placed at the posterior maxilla varying the surface treatment only: A randomized clinical trial. Clin Implant Dent Relat Res. 2017 Oct;19(5):770-5. https://doi.org/10.1111/cid.12510

39. Gupta RK, Padmanabhan TV. Resonance frequency analysis. Indian J Dent Res. 2011 Jul-Aug;22(4):567-73. https://doi.org/10.4103/0970-9290.90300

40. Ohta K, Takechi M, Minami M, Shigeishi H, Hiraoka $M$, Nishimura $M$ et al. Influence of factors related to implant stability detected by wireless resonance frequency analysis device. J Oral Rehabil. 2010 Feb;37(2):131-7. https://doi.org/10.1111/j.1365-2842.2009.02032.x 